\title{
Sleep-Disordered Breathing May Be Under-Recognized in Patients Who Wean From Prolonged Mechanical Ventilation
}

\author{
Montserrat Diaz-Abad MD, Avelino C Verceles MD, John E Brown MD, \\ and Steven M Scharf MD PhD
}

\begin{abstract}
BACKGROUND: The prevalence of sleep-disordered breathing (SDB) in patients with prolonged mechanical ventilation (PMV) is unknown. The aim of this study was to assess the frequency of SDB in patients admitted to a long-term acute care (LTAC) hospital who weaned from PMV. METHODS: Retrospective chart review was conducted of all PMV patients who had in-patient polysomnography (PSG) between January 2007 and May 2010. Main outcome measures included the frequency of SDB and tracheostomy decannulation. RESULTS: Nineteen patients were studied, age $53.4 \pm 13.4$ years, 11 males $\left(57.9 \%\right.$ ), with mean body mass index of $44.0 \pm 12.7 \mathrm{~kg} / \mathrm{m}^{2}$ (range 27.3-75.7). Eighteen patients (94.7\%) demonstrated SDB as evidenced by obstructive sleep apnea (OSA), with a median respiratory disturbance index (RDI) of 24.2 events/h (range 5.9-82.0 events/ h). Fourteen patients underwent successful positive airway pressure titration, with improvement in the median RDI to 0.9 events/h (range $0.0-9.1$ events/h) $(P<.001)$. Seventeen patients $(89.5 \%)$ were decannulated without adverse event. CONCLUSIONS: There may be a high prevalence of unrecognized SDB in patients who are candidates for decannulation after weaning from PMV. Key words: prolonged mechanical ventilation; sleep-disordered breathing; obstructive sleep apnea; polysomnography; tracheostomy decannulation; long-term acute-care hospital; respiratory failure. [Respir Care 2012; 57(2):229-237. () 2012 Daedalus Enterprises]
\end{abstract}

\section{Introduction}

There is an increasing number of patients who require prolonged mechanical ventilation (PMV), ${ }^{1}$ defined as mechanical ventilation for $\geq 21$ days. ${ }^{2}$ Patients who require PMV following a catastrophic illness are considered chronically critically ill $^{3}$ and are frequently cared for in long-term acute care (LTAC) hospitals. ${ }^{1}$ These patients have multiple comorbidities, with low weaning rates and poor outcomes. ${ }^{4,5}$

The presence of sleep-disordered breathing (SDB) could limit successful weaning from mechanical ventilation and

The authors are affiliated with the Sleep Disorders Center, Division of Pulmonary and Critical Care Medicine, University of Maryland School of Medicine, Baltimore, Maryland.

The authors have disclosed no conflicts of interest.

Correspondence: Montserrat Diaz-Abad MD, Sleep Disorders Center, Division of Pulmonary and Critical Care Medicine, University of Maryland School of Medicine, 685 West Baltimore Street, MSTF 800, Baltimore MD 21201. E-mail: mdiaz@medicine.umaryland.edu.

DOI: $10.4187 /$ respcare. 01260 decannulation, due to chronic and recurrent hypoxia and hypoventilation. The prevalence of undiagnosed SDB is high and increasing among middle age men and women, ${ }^{6}$ with obesity a major risk factor. A high prevalence of SDB, including obstructive sleep apnea (OSA), has been demonstrated in obese patients with acute respiratory failure $^{7-9}$ and in hospitalized patients in acute care facilities. ${ }^{10}$ Hence, it may be advisable to screen patients who wean from PMV with polysomnography (PSG) to evaluate for SDB prior to decannulation. To date, there are few data evaluating the prevalence of SDB in the PMV population.

The aim of this study was to determine the prevalence of SDB in a group of patients considered candidates for decannulation following weaning from PMV. We hypothesized that there would be a high prevalence of SDB in these patients.

\section{Methods}

The study was conducted at University Specialty Hospital, an LTAC facility affiliated with the University of Maryland Medical System. University Specialty Hospital 
has a pulmonary rehabilitation and ventilator weaning unit. There is a fully accredited American Academy of Sleep Medicine sleep laboratory located at University Specialty Hospital. The University of Maryland institutional review board approved this study.

\section{Study Design and Patient Selection}

We performed a retrospective chart review of polysomnographic reports and medical records of all patients $\geq 18$ years who weaned from PMV and had an in-patient PSG performed between January 2007 and May 2010.

\section{Patient Characteristics}

Data collected included demographic information, admission blood chemistry and hematologic panels, cause of respiratory failure, major comorbidities, height and weight, hospital stay, duration of tracheostomy and mechanical ventilation, time from hospitalization to polysomnography, type of tracheostomy, PSG findings, and decannulation and discharge outcomes. The age-adjusted Charlson comorbidity index ${ }^{11}$ was calculated based on the comorbidities documented on admission to the LTAC hospital. Stay at the LTAC hospital was calculated from the date of the patient's initial admission to the date of final discharge.

See the Related Editorial on Page 326

Inclusion criteria were: respiratory failure requiring $\mathrm{PMV} \geq 21$ days with a tracheostomy in place, or recently weaned from PMV with a tracheostomy still present on admission to the LTAC hospital; candidate for decannulation; baseline PSG performed.

Exclusion criteria were: pre-hospital diagnosis of SDB by PSG; use of positive airway pressure (PAP) or mechanical ventilation at home; and chronic tracheostomy prior to PMV.

\section{Weaning and Decannulation}

Patients were considered weaned if they achieved $\geq 7$ days off ventilatory support. ${ }^{2}$ Patients were followed by a board-certified pulmonologist, as consultant to a hospitalist. All weaned patients who were considered stable from a respiratory and medical standpoint underwent evaluation for decannulation, including direct laryngoscopy by an otorhinolaryngologist, with tracheostomy down-sizing, and consultation with a speech-language pathologist. All tracheostomies were cuffless, single cannula, and unfenestrated. Tracheostomy capping trials were conducted with increasing duration. Once 24 hours of continuous tracheostomy capping were tolerated, the tracheostomy was un-

\section{QUICK LOOK}

\section{Current knowledge}

Sleep-disordered breathing in mechanically ventilated patients is increasingly recognized as an important comorbidity.

\section{What this paper contributes to our knowledge}

Following prolonged mechanical ventilation, candidates for decannulation have a high prevalence of sleepdisordered breathing. In this study the presence of sleep-disordered breathing did not prevent successful decannulation.

capped at night until the PSG study. Daytime arterial blood gas was done within one week after discontinuation of mechanical ventilation, at the discretion of the treating physician.

Patients considered for decannulation underwent diagnostic PSG with the tracheostomy capped. In 3 cases, the patients had been decannulated within days prior to the diagnostic PSG. To be considered candidates for inlaboratory PSG, patients had to be alert, oriented, and cooperative, with no contraindications for CPAP therapy or noninvasive ventilation (NIV) if required. In addition, they had to be: moderately independent with transfers to and from the bed; able to use the bathroom independently or with the assistance of one person, or had indwelling urinary catheter; and no requirement for intravenous fluids or medications during the PSG.

\section{Polysomnogram}

Fully attended polysomnography was performed with the tracheostomy in place and capped, except in the 3 recently decannulated patients. PSG was done following standard technique ${ }^{12}$ using a Healthdyne ALICE 4 computerized polysomnographic system (Philips Respironics, Andover, Massachusetts). The montage included electroencephalography leads $\mathrm{C} 4 \mathrm{~A} 1, \mathrm{C} 3 \mathrm{~A} 2, \mathrm{O} 2 \mathrm{~A} 1$, and $\mathrm{O} 1 \mathrm{~A} 2$, right and left electrooculograms, submentalis electromyography, right and left leg electromyography, one-lead electrocardiography, air flow by nasal pressure transducer and oronasal thermistor, rib cage and abdominal respiratory effort, continuous pulse oximetry, snore microphone, and body position. End-tidal carbon dioxide $\left(\mathrm{P}_{\mathrm{ETCO}_{2}}\right)$ monitoring was recorded at the discretion of the ordering physician. Hypoventilation during sleep was defined as a $\geq 10 \mathrm{~mm} \mathrm{Hg}$ increase of the $\mathrm{P}_{\mathrm{aCO}_{2}}$ during sleep, in comparison to an awake supine value at the beginning of the study, using the $\mathrm{P}_{\mathrm{ETCO}_{2}}$ as a surrogate measure. ${ }^{12}$ 
Table 1. Patients

\begin{tabular}{|c|c|}
\hline Male, no. (\%) & $11(57.9)$ \\
\hline \multicolumn{2}{|l|}{ Race, no. } \\
\hline Black & 10 \\
\hline White & 8 \\
\hline Other & 1 \\
\hline Age, mean $\pm \mathrm{SD}$ (range), y & $53.4 \pm 13.4(28-73)$ \\
\hline Stay prior to LTAC, median (range), d & $39(11-223)$ \\
\hline $\begin{array}{l}\text { Duration of mechanical ventilation prior to } \\
\text { LTAC, median (range), d }\end{array}$ & $34(11-209)$ \\
\hline $\begin{array}{l}\text { Time to tracheostomy, mean } \pm \mathrm{SD} \\
\text { (range), d }\end{array}$ & $17 \pm 9(6-38)$ \\
\hline $\begin{array}{l}\text { Duration of tracheostomy prior to LTAC, } \\
\text { median, (range), d }\end{array}$ & $20(4-217)$ \\
\hline History of tobacco use, no. (\%) & $8(42.1)$ \\
\hline Hemoglobin, mean $\pm \mathrm{SD}$ (range), g/dL & $9.9 \pm 1.9(7.2-15.6)$ \\
\hline Albumin, mean $\pm \mathrm{SD}$ (range), g/dL & $2.5 \pm 0.5(1.4-3.6)$ \\
\hline $\mathrm{P}_{\mathrm{aO}_{2}} / \mathrm{F}_{\mathrm{IO}_{2}}$, mean $\pm \mathrm{SD}$ (range), mm Hg & $250 \pm 93(140-438)$ \\
\hline $\begin{array}{l}\text { Body mass index, mean } \pm \mathrm{SD} \text { (range), } \\
\mathrm{kg} / \mathrm{m}^{2}\end{array}$ & $44.0 \pm 12.7(27.3-75.7)$ \\
\hline $\begin{array}{l}\text { Prolonged mechanical ventilation on } \\
\text { admission, no. }(\%)\end{array}$ & $14(73.7)$ \\
\hline $\begin{array}{l}\text { Acute hypercapnic respiratory failure, } \\
\text { no. }(\%)\end{array}$ & $5(26.3)$ \\
\hline $\begin{array}{l}\text { Charlson comorbidity index, mean } \pm \text { SD } \\
\text { (range) }\end{array}$ & $4 \pm 2.6(0-9)$ \\
\hline
\end{tabular}

Sleep scoring was performed according to the system of Rechtshaffen and Kales, ${ }^{13}$ as modified in 2007. ${ }^{12}$ Respiratory events were scored as apneas (decrease in air flow to $\leq 10 \%$ of baseline for $\geq 10 \mathrm{~s}$ ), hypopneas $(\mathrm{H})$ (decrease in air flow to $10-70 \%$ of baseline associated with $\geq 4 \%$ desaturation), or respiratory event related arousals (RERAs, decrease in air flow to $10-70 \%$ of baseline with either 3\% desaturation or terminal arousals). Obstructive apneas (OA) were scored if the termination in air flow was associated with continued or increased respiratory effort throughout the entire period of absent flow. A central apnea (CA) was scored if it was associated with absent respiratory effort throughout the entire period of absent flow. A mixed apnea (MA) was scored if it was associated with absent inspiratory effort in the initial portion of the event, followed by resumption of inspiratory effort in the latter portion of the event.

Sleep apnea severity was quantified according to the respiratory disturbance index (RDI $=$ [number of apneas + number of hypopneas + number of RERAs] per hour of sleep). OSA was diagnosed if the RDI was $\geq 5$ events/h. Mild OSA was defined as an RDI 515 events/h, moderate as RDI $15-30$ events/h, and severe OSA as RDI $>30$ events/h. Oxygen desaturation was quantified as total sleep time spent with $\leq 90 \%$ oxygen
Table 2. Major Causes of Respiratory Failure

\begin{tabular}{lc}
\hline \hline \multicolumn{1}{c}{ Major Cause of Respiratory Failure } & No. \\
\hline COPD exacerbation & 2 \\
Multiple trauma with pulmonary contusion & 2 \\
Necrotizing fasciitis & 2 \\
Pancreatitis & 2 \\
Pneumonia & 2 \\
Septic shock & 2 \\
Acute on chronic renal failure & 1 \\
Aspiration & 1 \\
Bowel obstruction with perforation & 1 \\
Cerebrovascular accident & 1 \\
COPD vs congestive heart failure exacerbation & 1 \\
Liver biopsy with hemorrhage & 1 \\
Obesity hypoventilation syndrome & 1 \\
\hline
\end{tabular}

Table 3. Major Comorbidities Present on Admission to the LTAC Hospital

\begin{tabular}{lr}
\hline \hline \multicolumn{1}{c}{ Comorbidity } & No. \\
\hline Hypertension & 12 \\
Diabetes mellitus & 11 \\
Renal insufficiency & 6 \\
Congestive heart failure & 5 \\
Hyperlipidemia & 5 \\
COPD & 4 \\
Asthma & 2 \\
Cancer & 2 \\
Cerebrovascular accident & 2 \\
Coronary artery disease & 2 \\
Paraplegia/hemiplegia & 2 \\
Peripheral vascular disease & 2 \\
Hypothyroidism & 1 \\
Solid organ transplant & 1 \\
\hline
\end{tabular}

Table 4. LTAC Hospital Stay*

\begin{tabular}{lc}
\hline \hline LTAC stay & $106(28-834)$ \\
LTAC duration of mechanical ventilation & $31(7-384)$ \\
LTAC duration of tracheostomy & $82(23-497)$ \\
Decannulated, no. $(\%)$ & $17(89.5)$ \\
Time admission to PSG & $62(16-491)$ \\
Time PSG to decannulated & $19(1-50)$ \\
Total duration mechanical ventilation & $69(29-476)$ \\
Total time to PSG & $120(42-515)$ \\
Total duration tracheostomy & $101(37-518)$
\end{tabular}

* Values are median (range), unless otherwise noted

Total $=$ acute hospitalization + long-term acute care hospital $($ LTAC) hospitalization PSG $=$ polysomnogram

saturation during sleep, lowest event related oxygen saturation, and mean oxygen saturation during the study. Periodic limb movements in sleep (PLMS) were scored ${ }^{12}$ and quantified per hour of sleep (PLM index). PLMS was reported for PLM index $\geq 15 .{ }^{14}$ Following a diagnosis 
Table 5. Polysomnography Results

\begin{tabular}{|c|c|c|}
\hline Variables & PSG Baseline & PAP Titration \\
\hline Respiratory disturbance index, median (range), events/h* & $23.8(4.2-82.0)$ & $0.9(0.0-9.1)$ \\
\hline Apnea-hypopnea index, median (range), events $/ \mathrm{h}$ & $14.1(3.5-65.7)$ & NA \\
\hline Minimum $\mathrm{S}_{\mathrm{pO}_{2}}$, mean $\pm \mathrm{SD}$ (range), $\%$ & $79 \pm 13(45-97)$ & $85 \pm 7(71-97)$ \\
\hline Time with $\mathrm{S}_{\mathrm{pO}_{2}}<90 \%$, median (range), min & $14(0-172)$ & $4(0-211)$ \\
\hline Mean $\mathrm{S}_{\mathrm{pO}_{2}}$, mean $\pm \mathrm{SD}$ (range), $\%$ & $94 \pm 3(89-98)$ & $93 \pm 4(86-99)$ \\
\hline $\mathrm{O}_{2}$ use during PSG, no. (\%) & $5(26.3)$ & $3(27.3)$ \\
\hline Total sleep time, mean \pm SD (range), min & $238 \pm 62(112-332)$ & $253 \pm 58(154-336)$ \\
\hline Sleep latency, median (range), min & $10(1-178)$ & $19(1-47)$ \\
\hline Sleep efficiency, mean \pm SD (range), $\%$ & $68 \pm 18(29-75)$ & $72 \pm 16(41-91)$ \\
\hline REM latency, median (range), min & $102(34-300)$ & $69(33-221)$ \\
\hline Wake time after sleep onset, median (range), min & $50(5-256)$ & $53(14-216)$ \\
\hline Wake, median (range), $\%$ & $25.0(9.1-70.6)$ & $30.5(8.9-91.5)$ \\
\hline \multicolumn{3}{|l|}{ Non-REM sleep stage } \\
\hline $\mathrm{N} 1$, median (range), \% & $3.6(0.4-41.5)$ & $3.8(1.5-61.0)$ \\
\hline $\mathrm{N} 2$, mean $\pm \mathrm{SD}$ (range), $\%$ & $43.8 \pm 16.1(7.3-66.9)$ & $50.3 \pm 12.5(36.2-68.7)$ \\
\hline N3, median (range), $\%$ & $4.9(0.0-40.3)$ & $5.3(0.0-17.8)$ \\
\hline REM sleep, median (range), $\%$ & $4.4(0.0-35.2)$ & $11.8(0.0-19.6)$ \\
\hline OSA, no. $(\%)$ & $18(94.7)$ & NA \\
\hline Mild OSA, no. (\%) & $2(10.5)$ & NA \\
\hline Moderate OSA, no. (\%) & $9(47.4)$ & NA \\
\hline Severe OSA, no. (\%) & $7(36.8)$ & NA \\
\hline \multicolumn{3}{|l|}{$\begin{array}{l}* P<.001 . \\
\text { PSG }=\text { polysomnogram } \\
\text { PAP = positive airway pressure } \\
\text { REM = rapid-eye movement sleep } \\
\text { OSA = obstructive sleep apnea } \\
\text { NA = not applicable }\end{array}$} \\
\hline
\end{tabular}

of OSA, patients were offered a PAP titration study as indicated.

Oxygen was administered during the sleep study by physician's order, if the patient was on oxygen continuously prior to the study, or if oxygen saturation decreased to $<80 \%$ without rebound for $\geq 5 \mathrm{~min}$, per sleep laboratory protocol.

\section{Statistics/Data Analysis}

Normally distributed data (Kolmogorov-Smirnov test) were expressed as mean $\pm \mathrm{SD}$, with range. Non-normally distributed data were expressed as median and range. The Student $t$ test for unpaired variables was used to compare 2 groups of normally distributed data. The Mann-Whitney rank sum test was used to compare 2 groups of nonnormally distributed data. Association between variables was tested by calculating Pearson correlation coefficients by the least squares technique. Linear and logistic regressions were done with continuous and qualitative data, respectively. Statistical analysis was conducted using SigmaPlot 11.0 (Systat Software, San Jose, California). The null hypothesis was rejected at the $5 \%$ level.

\section{Results}

Thirty-four patients with PMV underwent a PSG while in-patient during the study period. Among these, we excluded 15 patients: 13 patients had a previous diagnosis of SDB, one patient was on home invasive ventilation, and one had a chronic tracheostomy prior to acute hospitalization. The cohort therefore consisted of 19 patients meeting the selection criteria. The mean age was $53.4 \pm 13.4$ years, with 11 men (57.9\%). Five patients had weaned from PMV within a few days prior to admission to the LTAC facility. The mean body mass index (BMI) was $44.0 \pm 12.7 \mathrm{~kg} / \mathrm{m}^{2}$. Two patients were not obese (BMI $\left.<30 \mathrm{~kg} / \mathrm{m}^{2}\right)$. The median stay prior to transfer to the LTAC facility was 39 days. Patient characteristics are shown in Table 1. There were varied causes of respiratory failure, as shown in Table 2. Patients had multiple comorbidities on admission to the LTAC hospital, as shown on Table 3, with a mean Charlson comorbidity index of $4.0 \pm 2.6$.

Median stay at the LTAC facility was 106 days. In the 14 patients weaned in the LTAC, median time to weaning was 31 days. Table 4 gives the details of the LTAC hospital LOS. Eighteen patients underwent full night diagnos- 
tic PSG, and one patient had a split-night study with a diagnostic and therapeutic portion.

Only one patient had a negative study (BMI $=43.5 \mathrm{~kg} /$ $\mathrm{m}^{2}$ ) for SDB. Eighteen patients (94.7\%) had SDB evident on PSG, which was OSA in all cases, with a median RDI of 24.2 events/h (range 5.9-82.0 events/h). BMI was not associated with the RDI. The following sleep diagnoses were also present: 3 patients had PLMS; one patient each: extensive fragmentary myoclonus, bruxism, alpha sleep. Five patients used supplemental oxygen 2-4 L/min nasal cannula during the baseline sleep study. One patient who was not on supplemental oxygen was noted to have several episodes of oxygen desaturation $<90 \%$ without obvious SDB events. There was no difference in RDI based on oxygen use during PSG. Table 5 shows the PSG results. The median number of SDB events per PSG were: OA (56) $>\mathrm{H}(11)>$ RERA (9) $>$ CA (0) $>$ MA (0). There was heavy snoring in 10 patients, moderate in 2 , mild/not significant in 6 , and not recorded in 1 . Five patients had $\mathrm{P}_{\mathrm{ETCO}_{2}}$ monitoring during their baseline study, which did not show hypoventilation. Seven patients had an arterial blood gas performed after weaning. The measured $\mathrm{P}_{\mathrm{CO}_{2}}$ was $47 \pm 5 \mathrm{~mm} \mathrm{Hg}$ (range $39-54 \mathrm{~mm} \mathrm{Hg}$ ), with 4 patients having a $\mathrm{P}_{\mathrm{CO}_{2}} \geq 45 \mathrm{~mm} \mathrm{Hg}$.

Fourteen of the 18 patients (77.8\%) with OSA underwent PAP titration, including the one patient with the split night study. In 4 patients PAP titration was not performed because of transfer or discharge prior to the planned titration. In 4 of the 14 patients an effective PAP pressure could not be determined: 2 patients underwent a second

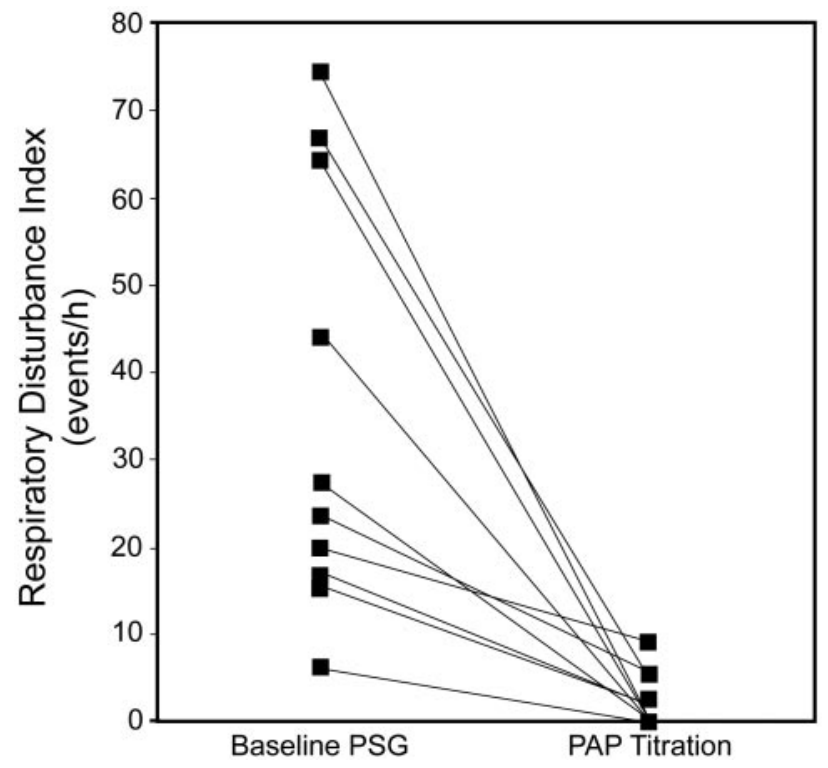

Fig. 1. Positive airway pressure (PAP) titrations were performed with a capped tracheostomy in place. PAP titration significantly improved the median respiratory disturbance index to 0.9 events/h (range 0.0-9.1 events/h) $(P<.001$, compared to baseline). $\mathrm{PSG}=$ polysomnography.
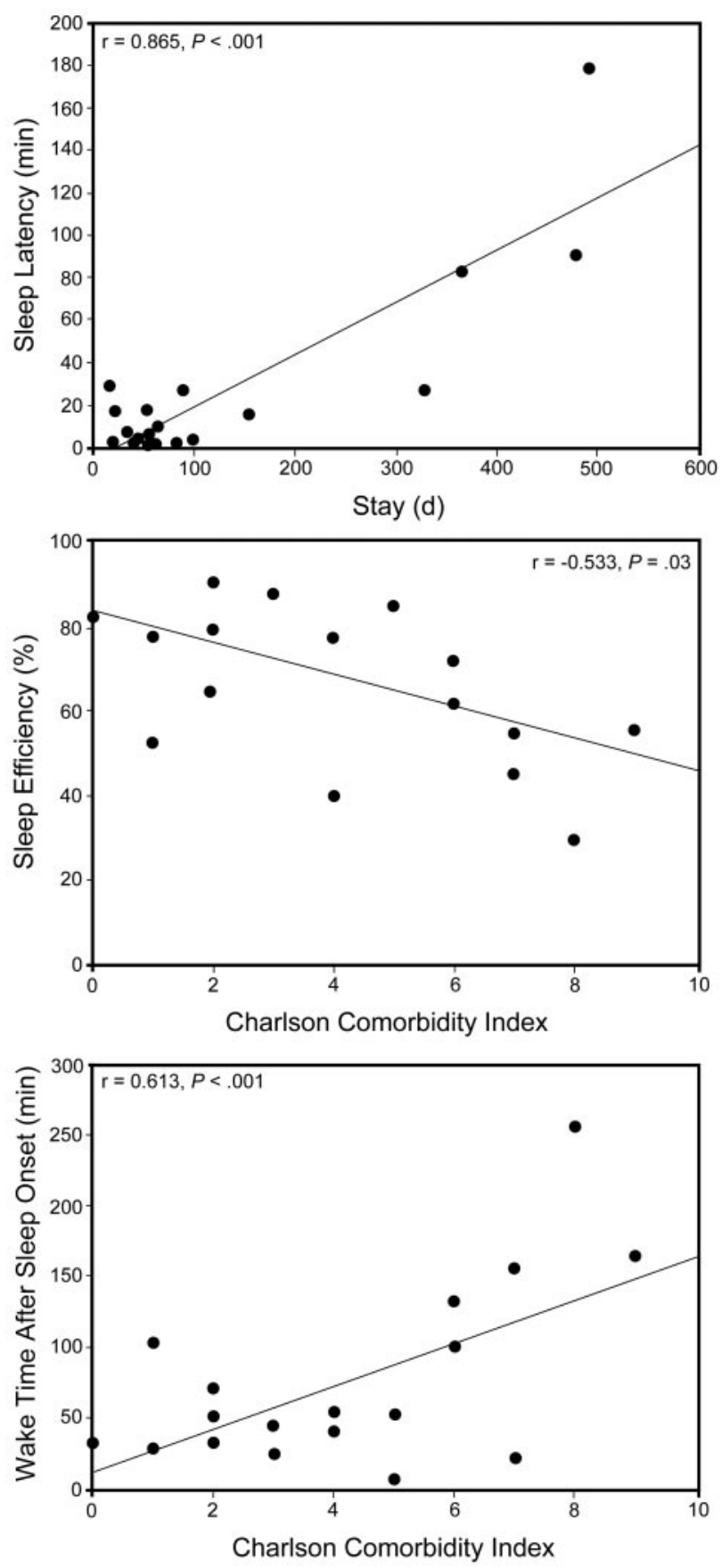

Fig. 2. Long-term acute care stay prior to the polysomnography night correlated with sleep latency, and Charlson comorbidity index was associated with decreased sleep efficiency and increased wake after sleep onset.

titration, which was effective, and 2 patients-both with moderate OSA- had follow up PAP autotitration.

PAP titrations were performed with a capped tracheostomy in place. PAP titration significantly improved the median RDI to 0.9 events/h (range $0.0-9.1$ events/h) $(P<.001$, compared to baseline, Fig. 1). 
Table 6. Patient List

\begin{tabular}{|c|c|c|c|c|c|c|c|c|}
\hline No. & Age & Sex & Race & Cause of Respiratory Failure & $\mathrm{CCI}$ & $\begin{array}{c}\mathrm{BMI} \\
\left(\mathrm{kg} / \mathrm{m}^{2}\right)\end{array}$ & Days* & $\begin{array}{l}\text { Tracheostomy } \\
\text { Device }\end{array}$ \\
\hline 1 & 35 & M & Black & Pneumonia & 1 & 48.9 & 22 & Shiley XLT 6 \\
\hline 2 & 53 & $\mathrm{~F}$ & Black & Septic shock & 4 & 44.3 & 491 & $\begin{array}{l}\text { Decannulated } 14 \mathrm{~d} \\
\text { prior to PSG }\end{array}$ \\
\hline 3 & 51 & M & Black & Cerebrovascular accident & 2 & 31.2 & 62 & $\begin{array}{l}\text { Decannulated } 3 \mathrm{~d} \\
\text { prior to PSG }\end{array}$ \\
\hline 4 & 51 & M & Black & COPD exacerbation & 7 & 36.8 & 477 & Shiley 6 \\
\hline 5 & 53 & M & White & Pancreatitis & 4 & 30.7 & 89 & $\begin{array}{l}\text { Decannulated } 6 \mathrm{~d} \\
\text { prior to PSG }\end{array}$ \\
\hline 6 & 63 & M & White & Acute on chronic renal failure & 7 & 56.1 & 54 & Shiley XLT 7 \\
\hline 7 & 28 & $\mathrm{~F}$ & Black & Aspiration & 0 & 75.7 & 16 & Shiley XLT \\
\hline 8 & 70 & $\mathrm{~F}$ & Black & Pneumonia & 5 & 43.5 & 83 & Shiley 6 \\
\hline 9 & 57 & $\mathrm{~F}$ & White & $\begin{array}{l}\text { Bowel obstruction with } \\
\text { perforation }\end{array}$ & 1 & 34.0 & 329 & Shiley 6 \\
\hline 10 & 67 & M & Other & Septic shock & 9 & 27.3 & 55 & Portex 6 \\
\hline 11 & 52 & $\mathrm{~F}$ & White & $\begin{array}{l}\text { Obesity hypoventilation } \\
\text { syndrome }\end{array}$ & 3 & 56.4 & 153 & Shiley 6 \\
\hline 12 & 54 & M & Black & COPD exacerbation & 6 & 42.6 & 40 & Shiley 6 \\
\hline 13 & 33 & M & White & Necrotizing fasciitis & 1 & 55.5 & 98 & Shiley XLT 6 \\
\hline 14 & 73 & $\mathrm{~F}$ & White & Necrotizing fasciitis & 8 & 43.4 & 64 & Bivona 7 \\
\hline 15 & 34 & $\mathrm{~F}$ & Black & $\begin{array}{l}\text { Multiple trauma with } \\
\text { pulmonary contusion }\end{array}$ & 2 & 42.7 & 364 & Shiley XLT 5 \\
\hline 16 & 61 & M & White & $\begin{array}{l}\text { Multiple trauma with } \\
\text { pulmonary contusion }\end{array}$ & 2 & 55.2 & 19 & Shiley XLT 6 \\
\hline 17 & 47 & M & Black & $\begin{array}{l}\text { COPD vs congestive heart } \\
\text { failure exacerbation }\end{array}$ & 3 & 53.4 & 56 & Shiley 8 \\
\hline 18 & 72 & $\mathrm{~F}$ & White & Pancreatitis & 5 & 30.6 & 43 & Portex 7 \\
\hline 19 & 60 & M & Black & Liver biopsy with hemorrhage & 6 & 27.9 & 33 & $\begin{array}{l}\text { Portex } 6 \\
\text { (continued) }\end{array}$ \\
\hline
\end{tabular}

Hospital stay and the level of comorbidities, as reflected by the Charlson comorbidity index, did not correlate with the presence of SDB or the RDI. The LTAC hospital stay prior to the PSG night did correlate with the sleep latency, and the Charlson comorbidity index was associated with decreased sleep efficiency and increased wake time after sleep onset (Fig. 2).

Seventeen patients $(89.5 \%)$ were successfully decannulated without adverse events. Of the 2 patients not decannulated, one (RDI 5.9 events/h) had multiple infectious complications after the PSG. The other patient (without SDB, RDI 4.2 events/h) had worsening congestive heart failure requiring restarting mechanical ventilation several months later.
With regard to final disposition, 10 patients were discharged home, 4 patients were transferred to an acute-care hospital, 3 patients were transferred to another rehabilitation facility, and 2 previous nursing home residents were discharged to a nursing home. All patients who underwent a PAP titration study were started on PAP therapy during their stay and tolerated it well, except for the one patient not decannulated. All patients were discharged or transferred on PAP therapy, except for one patient transferred to an acute care facility. A description of all patients is available in Table 6.

\section{Discussion}

We found a $94.7 \%$ prevalence of SDB, all OSA, in an LTAC hospital population of patients who weaned from 
Table 6. Patient List (continued)

\begin{tabular}{|c|c|c|c|c|c|c|}
\hline No. & PSG Diagnosis & $\begin{array}{c}\text { RDI } \\
\text { (events/h) }\end{array}$ & $\begin{array}{l}\text { PAP Titration } \\
\quad\left(\mathrm{cm} \mathrm{H}_{2} \mathrm{O}\right)\end{array}$ & $\begin{array}{l}\text { PAP RDI } \\
\left(\mathrm{cm} \mathrm{H} \mathrm{H}_{2} \mathrm{O}\right) \\
\end{array}$ & Decannulated & Disposition \\
\hline 1 & $\mathrm{OSA} \dagger$ & 64.5 & $10 \dagger$ & 0.0 & Yes & Home \\
\hline 2 & OSA & 64.3 & 13 & 0.0 & Yes & Nursing home \\
\hline 3 & OSA & 39.9 & NA & NA & Yes & Rehabilitation \\
\hline 4 & OSA, PLMS, EFM & 8.3 & NA & NA & Yes & Acute \\
\hline 5 & OSA & 15.2 & Not determined, follow-up autotitration & & Yes & Rehabilitation \\
\hline 6 & OSA & 24.5 & Not determined, follow-up autotitration & & Yes & Nursing home \\
\hline 7 & OSA & 16.8 & 10 & 2.4 & Yes & Home \\
\hline 8 & Severe sleep fragmentation & 4.2 & NA & NA & No & Acute \\
\hline 9 & OSA & 19.9 & 6 & 9.1 & Yes & Home \\
\hline 10 & OSA & 66.6 & 20/16 (Second PAP titration) & 4.8 & Yes & Home \\
\hline 11 & OSA & 23.8 & NA & NA & Yes & Home \\
\hline 12 & $\begin{array}{l}\text { OSA } \\
\text { Study done in geriatrics chair } \\
\text { due to orthopnea } \dagger\end{array}$ & 16.9 & $7 \dagger$ & 1.8 & Yes & Acute \\
\hline 13 & $\begin{array}{l}\text { OSA } \\
\text { Split study. Baseline portion } \dagger\end{array}$ & 74.6 & 9 & 0.0 & Yes & Home \\
\hline 14 & OSA, PLMS & 15.5 & 10 & 2.0 & Yes & Rehabilitation \\
\hline 15 & OSA, bruxism & 5.9 & 4 & 0.0 & No & Acute \\
\hline 16 & OSA & 27.3 & $9 / 6$ & 0.0 & Yes & Home \\
\hline 17 & OSA & 82.0 & NA & NA & Yes & Home \\
\hline 18 & $\mathrm{OSA} \dagger$ & 44.4 & 12 & 0.0 & Yes & Home \\
\hline 19 & OSA, alpha sleep $\dagger$ & 23.5 & 12 (Second PAP titration) & 5.6 & Yes & Home \\
\hline $\begin{array}{l}* \text { Days } \\
\dagger \text { Stud } \\
\text { CCI }= \\
\text { BMI }= \\
\text { PSG }= \\
\text { RDI }= \\
\text { PAP }= \\
\text { XLT }= \\
\text { OSA }= \\
\text { NA }= \\
\text { PLMS } \\
\text { EFM }\end{array}$ & $\begin{array}{l}\text { days from long-term acute care hospital adn } \\
\text { done with } 2-4 \mathrm{~L} / \mathrm{min} \text { oxygen. } \\
\text { Charlson comorbidity index } \\
\text { body mass index } \\
\text { polysomnogram } \\
\text { espiratory disturbance index (events/h) } \\
\text { positive airway pressure titration study } \\
\text { extended length } \\
\text { obstructive sleep apnea } \\
\text { Tot applicable. } \\
\text { = periodic limb movements in sleep } \\
\text { extensive fragmentary myoclonus }\end{array}$ & to polysomnograr & & & & \\
\hline
\end{tabular}

PMV. In most of our patients, SDB was treated successfully with PAP therapy, with subsequent tracheostomy decannulation and discharge to home. We did not find a correlation between BMI and RDI. However, the overwhelming majority of the patients were obese. In the following discussion we consider these findings in the light of the currently available literature.

Previous studies have reported high prevalences of SDB and OSA in acute care settings. A review of in-patient PSGs performed in an acute-care hospital ${ }^{10}$ found a frequency of $77 \%$ of SDB (95\% OSA) in a mostly obese patient population. A few case series have investigated the relationship between acute respiratory failure and SDB. BaHammam et al reported 11 obese patients who suffered an episode of hypercapnic respiratory failure who required invasive or noninvasive mechanical ventilation. Among these, 10 had no prior history of SDB, but all were found to have a diagnosis of SDB on PSG. ${ }^{7}$ In 9 patients admitted to an ICU with hypercapnic respiratory failure, Buckle et al reported that all had SDB on PSG. ${ }^{9}$ Resta et al also showed that $100 \%$ of 14 obese patients admitted with acute hypercapnic respiratory failure had SDB on portable PSG. ${ }^{8}$ In the 3 latter studies, patients were specifically selected on the basis of clinical suspicion for SDB and had 
been admitted with hypercapnic respiratory failure. By contrast, in the present series of PMV patients, only 5 (35.7\%) had been admitted to the acute-care hospital with hypercapnic respiratory failure. Indeed, the majority of the diagnoses associated with respiratory failure were not specifically respiratory. Finally, the overall prevalence of SDB in patients with morbid obesity (BMI $\geq 40 \mathrm{~kg} / \mathrm{m}^{2}$ ) in a middle-age population, comparable in age to ours, ranges from $42-77 \%$ in men and $16-46 \%$ in women, depending on the definition used. ${ }^{15}$ Given the small numbers in our study, we cannot comment on whether the prevalence in our patient group is significantly different than previously reported.

There were a minority of patients who were on supplemental oxygen or had oxygen desaturation without obvious SDB events on their baseline sleep study. Whether this represents hypoventilation from OHS, cardiopulmonary disease, or diaphragmatic dysfunction is unclear. Hypoventilation due to residual diaphragmatic weakness, or critical illness polyneuropathy/myopathy ${ }^{16,17}$ might have contributed to hypoventilation and SDB in some of these patients. $\mathrm{P}_{\mathrm{ETCO}_{2}}$ monitoring was not part of routine PSG in these patients, and we cannot comment further on the prevalence of nocturnal hypoventilation.

Although we were unable to rule out hypoventilation during sleep as a component of the SDB in our patient group, OSA appeared to be the predominant form of SDB, at least in most patients. There were much more obstructive apneas than hypopneas and RERAs in the PSGs. There was also no difference in the type of SDB events and overall RDI between patients with or without oxygen during the sleep studies. Further studies with measurement of $\mathrm{P}_{\mathrm{aCO}_{2}}$, and invasive measurements of respiratory effort with evaluation of respiratory muscle strength and pulmonary function, may be needed to distinguish better different causes of SDB in the PMV population.

We also found a correlation between hospital stay prior to PSG and sleep onset latency on the diagnostic PSG. The reason for this is not clear. Possibly acclimatization to hospital routine, including nursing and respiratory care, medication effect, or circadian rhythm disturbances may lead to later sleep times with prolonged stay. We also found that increased comorbidity burden was associated with decreased sleep efficiency and increased wake time after sleep onset. These findings are consistent with the notion that symptoms associated with comorbidities (eg, dyspnea, pain, discomfort) can lead to sleep fragmentation. Decreased quality of sleep has been noted in critically ill patients in the ICU. ${ }^{18}$ However, there are few data on sleep quality in chronically ill patients on prolonged ventilatory support in other settings of care.

At our facility, PSG was part of the standard workup prior to decannulation in all eligible patients. Although patients were not selected to undergo a PSG based on symptoms of SDB, most of the patients in this series were obese and middle-aged. This could have been related at least in part to the extensive list of criteria required to undergo PSG in our institution. In our case series the vast majority of the diagnoses leading to respiratory failure were medical; only 2 patients had trauma as cause of their PMV, while none had traumatic brain injury. This could be in part a result of the requirement of intact mental status and moderate ability to transfer, although this cannot be said with certainty. In addition, our facility has the capability of caring for bariatric patients; thus morbidly obese patients are common in our institution. Because of its retrospective nature, we cannot exclude the possibility of selection bias in our study, with overrepresentation of obese patients, potentially increasing the reported incidence of SDB. Interestingly, the one patient who had a negative study was obese, while the 2 non-obese patients had OSA. Because of all of these restrictions, we cannot comment on the role of SDB screening in the PMV population as a whole, including patients with poor mental status or very limited mobility. Further, without a series of non-obese patients to act as control, we cannot comment on the actual prevalence of OSA in the entire cohort of PMV patients considered candidates for decannulation.

Our study is limited by sample size and lack of postdischarge follow-up. We cannot say whether the discovery of OSA made a long-term difference to rates of recurrent respiratory failure and hospitalization in our patients. However, in OSA discovered in the acute care setting after respiratory failure, Sampol et al demonstrated a decreased number of admissions in the 3 years following institution of CPAP/NIV, compared to the 3 years prior to discovery of OSA. In addition, among the patients who died on follow-up in this group, compliance with CPAP/NIV was worse, compared to survivors, suggesting that institution of appropriate therapy can improve mortality in patients with OSA and respiratory failure after discharge. ${ }^{19}$ Further study in larger patient groups is needed to explore these results.

\section{Conclusions}

In conclusion, patients who have weaned from prolonged mechanical ventilation may have an increased prevalence of SDB. Larger studies including a larger selection of non-obese patients should be done to determine the true incidence of SDB in these patients, and longerterm follow-ups should be done to determine the clinical importance of these findings.

\section{REFERENCES}

1. Kahn JM, Benson NM, Appleby D, Carson SS, Iwashyna TJ. Longterm acute care hospital utilization after critical illness. JAMA 2010; 303(22):2253-2259. 


\section{Sleep-Disordered Breathing May Be Under-Recognized}

2. MacIntyre NR, Epstein SK, Carson S, Scheinhorn D, Christopher K, Muldoon S. Management of patients requiring prolonged mechanical ventilation: report of a NAMDRC consensus conference. Chest 2005; 128(6):3937-3954.

3. Nierman DM. A structure of care for the chronically critically ill. Crit Care Clin 2002;18(3):477-491.

4. Scheinhorn DJ, Hassenpflug MS, Votto JJ, Chao DC, Epstein SK, Doig GS, Knight EB, Petrak RA; Ventilation Outcomes Study Group. Ventilation Outcomes Study Group. Ventilator dependent survivors of catastrophic illness transferred to 23 long-term care hospitals for weaning from prolonged mechanical ventilation. Chest 2007;131(1): 76-84.

5. Scheinhorn DJ, Hassenpflug MS, Votto JJ, Chao DC, Epstein SK, Doig GS, Knight EB, Petrak RA; Ventilation Outcomes Study Group; Ventilation Outcomes Study Group. Post-ICU mechanical ventilation at 23 long-term care hospitals: a multicenter outcomes study. Chest 2007;131(1):85-93.

6. Young T, Palta M, Dempsey J, Skatrud J, Weber S, Badr S. The occurrence of sleep-disordered breathing among middle-aged adults. N Engl J Med 1993;328(17):1230-1235.

7. BaHammam A, Syed S, Al-Mughairy A. Sleep-related breathing disorders in obese patients presenting with acute respiratory failure. Respir Med 2005;99(6):718-725.

8. Resta O, Guido P, Foschino Barbaro MP, Picca V, Talamo S, Lamorgese V. Sleep-related breathing disorders in acute respiratory failure assisted by non-invasive ventilation treatment: utility of portable polysomnographic system. Respir Med 2000;94(2):128-134.

9. Buckle P, Pouliot Z, Millar T, Kerr P, Kryger MH. Polysomnography in acutely ill intensive care unit patients. Chest 1992;102(1): 288-291.
10. Goring K, Collop N. Sleep disordered breathing in hospitalized patients. J Clin Sleep Med 2008;4(2):105-110.

11. Charlson ME, Pompei P, Ales KL, MacKenzie CR. A new method of classifying prognostic comorbidity in longitudinal studies: development and validation. J Chronic Dis 1987;40(5):373-383.

12. Iber C, Ancoli-Israel S, Chesson A, Quan S. for the American Academy of Sleep Medicine. The AASM manual for the scoring of sleep and associated events: rules, terminology and technical specifications, 1st edition. Westchester, IL: American Academy of Sleep Medicine; 2007.

13. Rechtschaffen A, Kales A. A manual of standardized terminology, techniques and scoring system for sleep stages of human subjects. Los Angeles: Brain Information Service/Brain Research Institute, University of California; 1968.

14. American Academy of Sleep Medicine. International classification of sleep disorders, 2nd edition. Diagnostic and coding manual. Westchester, IL: American Academy of Sleep Medicine; 2005.

15. Young T, Peppard PE, Taheri S. Excess weight and sleep-disordered breathing. J Appl Physiol 2005;99(4):1592-1599.

16. Powers SK, Kavazis AN, Levine S. Prolonged mechanical ventilation alters diaphragmatic structure and function. Crit Care Med 2009; 37(10 Suppl):S347-S353.

17. Ragette R. Patterns and predictors of sleep disordered breathing in primary myopathies. Thorax 2002;57(8):724-728.

18. Krachman SL, D'Alonzo GE, Criner GJ. Sleep in the intensive care unit. Chest 1995;107(6):1713-1720.

19. Sampol G, Rodés G, Ríos J, Romero O, Lloberes P, Morell F. Acute hypercapnic respiratory failure in patients with sleep apneas. Arch Bronconeumol 2010;46(9):466-472.

This article is approved for Continuing Respiratory Care Education credit. For information and to obtain your CRCE

(free to AARC members) visit www.RCJournal.com

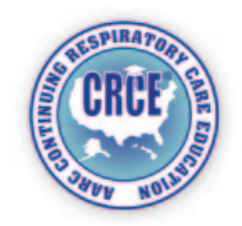

